\title{
SENECELLA CALANOIDES
}

\section{A RECENTLY DESCRIBED FRESH-WATER COPEPOD}

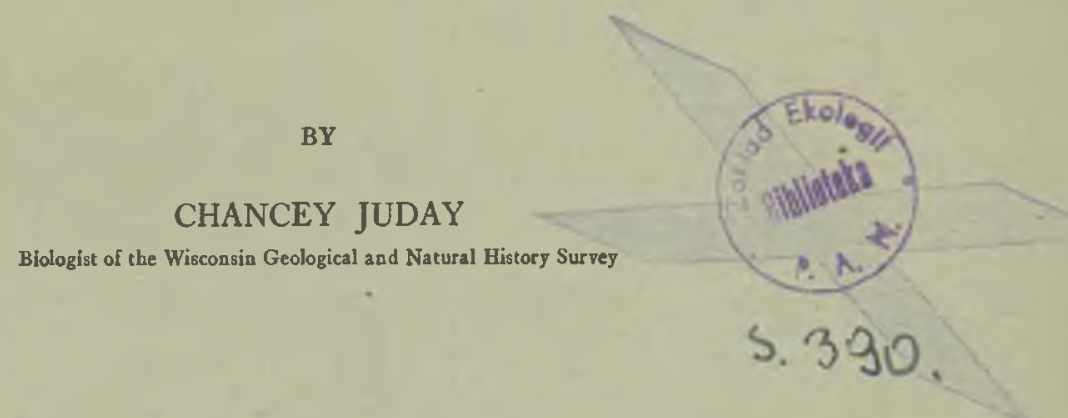

Dr. Kazimierz Gajl

No. 2541,-From the Proceedings of the United States National Museuin Vol. 66, Art. 4, pp. 1-6, with pla. 1-3

WASHINGTON

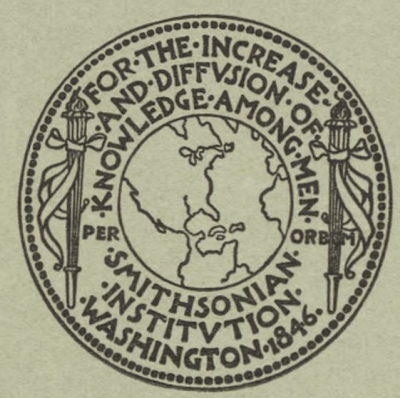

GOVERNMENT PRINTING OFFICE

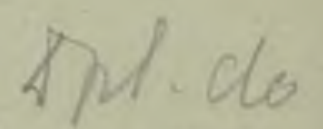

1925

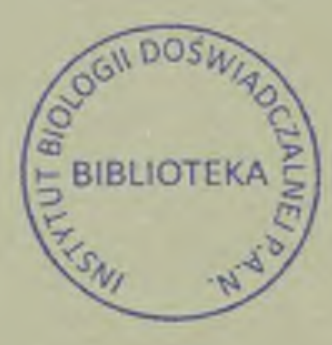


rcin.org.pl 


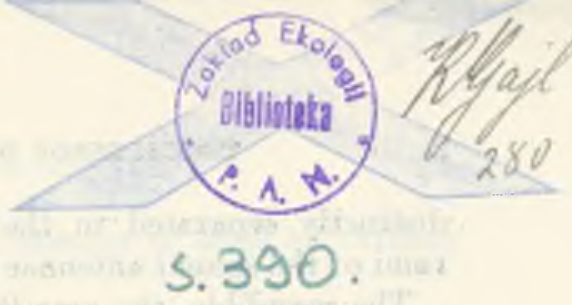

Dr. Kazimierz

\section{SENECELLA CALANOIDES, A RECENTLY DESCRIBED FRESH-WATER COPEPOD}

\section{By CHancey JUday}

Biologist of the Wisconsin Geological and Natural History Survey

During the summers of 1910 and 1918 limnological studies of the Finger Lakes of New York were made for the Cnited States Bureau of Fisheries. Plankton catches were obtained from the various lakes that were visited, and a recent taxonomic study of the copepods in this material led to the discovery of an interesting calanoid form which represented not only a new species but also a new genus of fresh-water Copepoda. This copepod was found in catches obtained from the lower water of 3 of the 10 lakes that were studied, namely, Seneca, Cayuga, and Owasco. It was briefly characterized in Science. ${ }^{1}$

\section{Genus SENECELLA Juday}

Senecella JUday, Science (n. s.), vol. 58, 1923, p. 205.

Generic characters of male and female.-The cephalothorax is nearly three times as long as its maximum width, evenly and gradually raulted anteriorly, without a rostrum or rostral filaments at the anterior end. The head is only indistinctly separated from the first thoracic segment. In the female the first thoracic segment is strongly carinated on its ventral surface. The abdomen is symmetrical, consisting of four segments in the female and five in the male, the fifth segment in the latter being very short. The caudal rami in both sexes are rather short; each ramus bears five terminal setae and a small seta on the upper surface near the middle of the inner edge, ciliated on the inner margin.

The first antennae are longer than the cephalothorax, with 25 segments. The right antenna is exactly like the left in the adult male. Each antenna bears 15 sensory appendages in the adult male, but only 7 in the female. The eighth and ninth segments are more

1 New Series, vol. 58,1923 , p. 205.

No. 254I.-PRoceedings U. S. National Museum. Vol. 66, ARt. 4 $9112-25$ 
distinctly separated in the male than in the female. The outer rami of the second antennae consist of 7 segments.

The mandible, the maxilla, and the first maxilliped of the adult male are greatly reduced. The terminal part of the second maxilliped consists of five short segments which are reflexed on the second basal segment in both sexes.

The inner ramus (endopodite) of the first pair of swimming legs consists of one segment, that of the second pair of two segments, and those of the third and fourth pairs of three segments. The outer ramus (exopodite) of the first to fourth pairs of swimming legs is three-segmented. The fifth pair of legs is absent in the female, but large and greatly modified in the adult male.

\section{SENECELLA CALANOIDES Juday}

Senecella calannides JudaY, Science (n. s.), vol. 58, 1923, p. 205.

One female has been selected as the type of the species and has been given Cat. No. 57\%07, U.S.N.M. There are in addition 10 paratypes, females, Cat. No. 57708. C.S.N.M., and 11 male specimens, Cat. No. 57709, U.S.N.M.

Characters of female.-In a dorsal view (pl. 1, fig. 1) the body is evenly rouncled in front, but it is rather sharply truncated posteriorly; in a side view (pl. 1 , fig. 2) the ventral margin is nearly straight, while the dorsal margin is evenly rounded both anteriorly and posteriorly. The last segment of the thorax bears only moderate sized lateral expansions.

The abdomen is made up of four segments. The first or genital segment is nearly as long as the other three combined and is somewhat dilated on the ventral surface, with the genital opening approximately in the middle of the segment. Caudal rami less than twice as long as broad. More than 200 females were examined for ovisacs, but none was found; it seems probable therefore that the eggs are not carried during the period of incubation in this form.

The first antenna (pl. 1, fig. 3 ) is made up of 25 segments, the eighth and ninth being somewhat coalesced. When reflexed, the antenma reaches the end of the first segment of the abdomen. Each antenna bears seven sensory appendages, one each on the second, fifth, ninth, twelfth, fourteenth, nineteenth, and twenty-fifth segments.

The second antenna (pl. 1, fig. 4) is medium sized; the inner ramus is somewhat broader than the outer. The outer ramus is made up of seven segments, of which the second and the seventh are the longest; the inner ramus is two-segmented.

The mandible (pl. 1, fig. 5) bears only a moderately expanded masticatory part; the cutting edge is armed with several teeth. 
The maxilla is foliaceous and bears a number of setae of various lengths. (pl. 1, fig. 6.)

The first maxilliped (pl. 2, fig. 7 ) is well developed and is armed with a number of plumose setae. The second maxilliped (pl. 2, ig. 8 ) is elongated and the terminal part is reflexed on the second basal segment.

The inner ramus of the first pair of swimming legs (pl. 2, fig. 9) has only one segment; it bears three setae on the inner margin and two at the apex. There is a ciliated prominence on the outer margin of this ramus. The penultimate segment of the outer ramus is armed with a spine at its outer distal angle.

The inner ramus of the second pair of swimming legs (pl. 2, fig. 10) has two segments: the first segment bears a plumose seta on its inner margin and the second has two setae on the inner margin, two at the apex, and one on the outer margin. The first and second segments of the outer ramus possess a spine of moderate size and one of minute size at the outer distal angle. The third segment has one spine on its outer margin and three terminal spines; the inner terminal spine is large and is armed with teeth on its outer margin.

The first basal segment of the third pair of swimming legs (pl. 2, fig. 11) bears a plumose seta on its inner margin as does that of the second pair of legs. The first basal segment of the fourth pair of legs (pl. 2, fig. 12) has a spine on the inner margin which is shaped somewhat like a spur; this pair of spines probably has some sexual function since one lies on either side of the genital opening when these legs are reflexed against the body.

The inner ramus of the third and fourth pairs of swimming legs is three-segmented; the armature is the same as that of the inner ramus of the second pair of legs with an extra seta on the additional segment. The outer ramus of the third and fourth pairs of legs is like that of the second pair.

The fifth pair of legs is absent in the female.

Length of female, 2.65 to 2.85 millimeters.

Characters of male.-The male is somewhat smaller and more slender than the female. (pl. 2, figs. 13 and 14.) The abdomen is made up of five segments; the first four are about equal in length, but the fifth is small. The genital opening is situated on the left side of the first abdominal segment. The caudal rami are small, only a little longer than broad.

The first antenna is made up of 25 segments (pl. 3, fig. 15); the right antenna is not modified in any way, but is exactly like the left. Each antenna bears 15 sensory appendages.

The second antenna is like that of the female. 
The mandible, the maxilla, and the first maxilliped are much reduced in the adult male. (pl. 3, figs. 16-18.) In immature males which are only 0.1 to 0.2 millimeter shorter than the adults, these mouth parts are like those of the female; this indicates that the reduction takes place during the final moult in transforming to an adult. Figure 16 shows that the masticatory part of the mandible is very weak and has only a small cutting edge.

The second pair of maxillipeds and the first three pairs of swimming legs of the male are like those of the female. The fourth pair of legs of the male differs from that of the female in that the first basal segment does not possess a spine on the inner margin, but it has instead a small, cuplike depression about two-thirds of the way toward the outer end.

The fifth pair of legs of the male (pl. 3, fig. 20) is unusually large, asymmetrical, and greatly modified for the transfer of the spermatophores. The proximal third of the first basal segment is fused. The second basal segment of the right leg is large, quadrangular, and about as long as broad. The inner ramus of the right leg is elongated, reaching beyond the second segment of the outer ramus, with the outer margin and the distal third hyaline. The first segment of the outer ramus of the right leg is elongated, subtriangular in outline, with a small spine on its outer margin. A narrow hyaline lamella arises at the inner distal angle of this segment and extends outward along the second segment and the base of the terminal hook. The second segment of the outer ramus is small and bears a small, inward-projecting spine at its outer distal angle; it also bears a long terminal hook which is recurved at the outer end.

The second basal segment of the left leg is oblong, nearly twice as long as broad. The inner ramus of this leg consists of a broad, somewhat triangular basal portion, with a digitiform process at the outer distal angle; the outer margin and the fingerlike process are hyaline. The second segment of the outer ramus of the left leg is larger than the first and possesses a protuberance at the inner proximal angle; the second segment terminates in a conical process, with a small spine at the base of this process.

Length of adult male, 2.45 to 2.55 millimeters.

The fifth pair of legs of an immature male 2.35 millimeters long is shown in plate 3 , figure 19 . These appendages are still comparatively simple when this stage is reached, the chief modification taking place between this and the adult stage. The first antenna of an immature male of this size is like that of the female, with seven sensory appendages and with the eighth and ninth segments 
somewhat coalesced. Likewise the mandible, the maxilla, and the first maxilliped are like those of the female.

The absence of the fifth pair of swimming legs in the female, the reduction of three oral appendages in the adult male, and the fact that the right member of the first pair of antennae is like the left in the adult male serve to distinguish Senecella calanoides from the other fresh-water Calanoida that are known at the present time. These characters give it a much closer relationship to some of the marine calanoids than to the other fresh-water members of this group.

Distribution.-Senecella calanoides was obtained from the lower water of Seneca Lake and of Cayuga Lake, N. Y., in September, 1908, in August, 1910, and in July, 1918, and from Owasco Lake in August, 1910. Through the kindness of N. K. Bigelow of the Royal Ontario Museum of Zoology and of Dr. W. A. Clemens of the University of Toronto, plankton material containing Senecella has been obtained from two Canadian lakes, namely, Lake Timagami and Lake Nipigon.

In a personal communication dated May 8, 1924, Dr. C. Dwight Marsh states that he collected immature specimens of an unknown copepod in Pine Lake, Michigan, in 1894, and in Lake Superior near Duluth, Minn., in 1898, and he now finds that these jurenile specimens are identical with those of Senecella calanoides from Seneca Lake.

In a recent note ${ }^{2}$ attention was called to the fact that Senecella was not associated with Limnocalanus in the New York lakes, but the material from Lake Nipigon contains both forms, the latter being much more abundant than the former. In the New York lakes Senecella was not present in the upper 15 meters of water in the summer, but in Lake Nipigon it has been taken where the water was less than 2 meters deep.

EXPLANATION OF PLATES

PLATE 1

Fig. 1. Dorsal view of female, $\times 28$.

2. Side view of female, $\times 28$.

3. First antenna of female, $\times 43$.

4. Second antenna of female, $\times 75$.

5. Mandible of female, $\times 114$.

6. Maxilla of female, $\times 114$.

Science (new ser.), vol. 58, 1923, p. 205. 


\section{Plate 2}

FIG. 7. First maxilliped of female, $\times 114$.

8. Second maxilliped of female, $\times 114$.

9. Left member of first pair of sivimming legs of female, $\times \mathbf{7 5}$.

10. Left member of second pair of swimming legs of female, $\times 75$.

11. Left member of third pair of swimming legs of female, $\times 75$.

12. Left member of fourth pair of swimming legs of female, $\times 75$.

13. Dorsal view of adult male, $\times 28$.

14. Side view of adult male, $\times 28$.

\section{Plate 3}

Fig. 15. First antenna of adult male, $\times 43$.

16. Mandible of adult male, $\times 114$.

17. Maxilla of adult male, $\times 114$.

18. First maxilliped of adult male, $\times 114$.

19. Fifth pair of legs of immature male, $\times 75$.

20. Fifth pair of legs of adult male. $\times 75$.

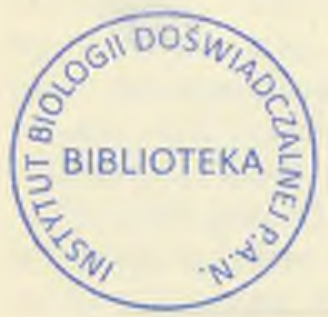




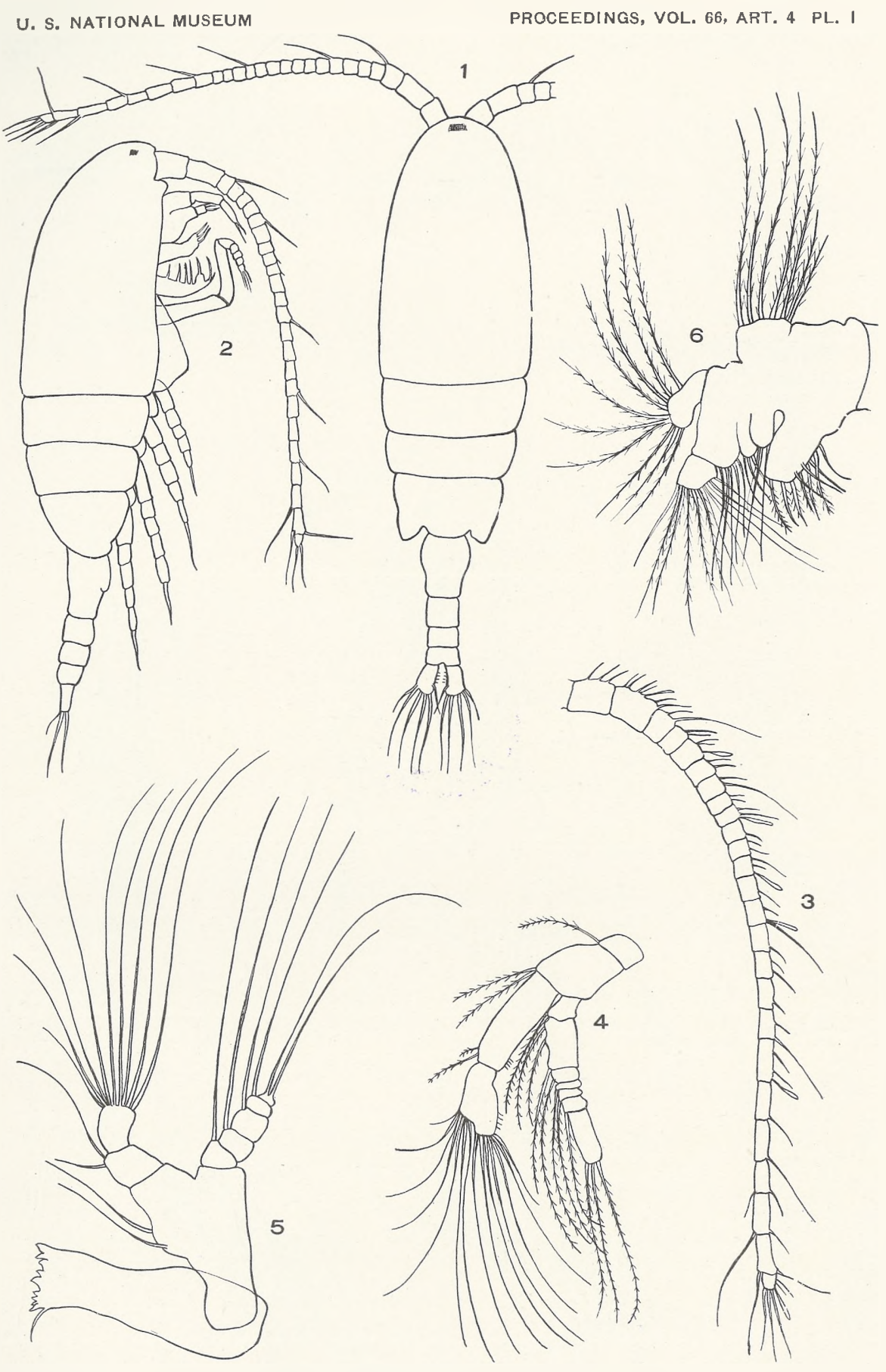

Female of Senecella calanoides

For explanation of plate see page 6 
U. S. NATIONAL MUSEUM
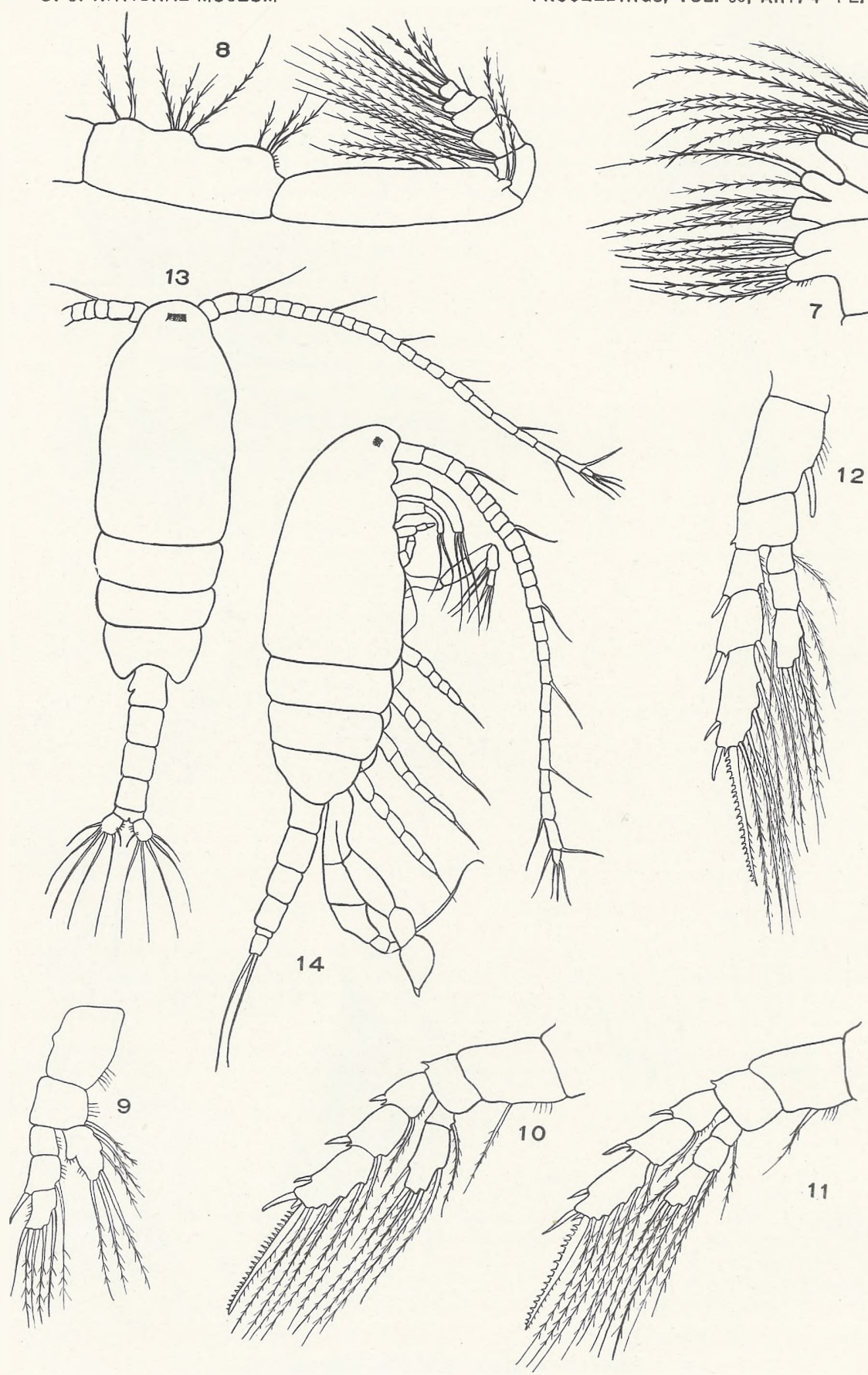

Male and female of Senecella calanoides

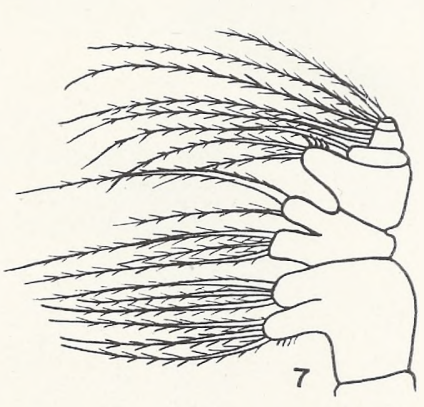

2 
U. S. NATIONAL MUSEUM

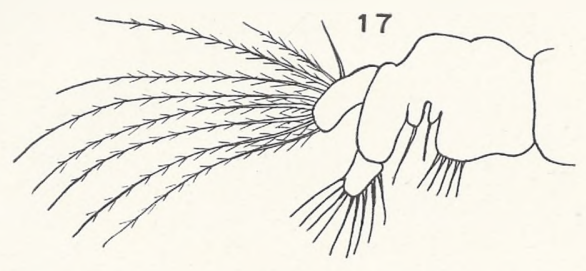

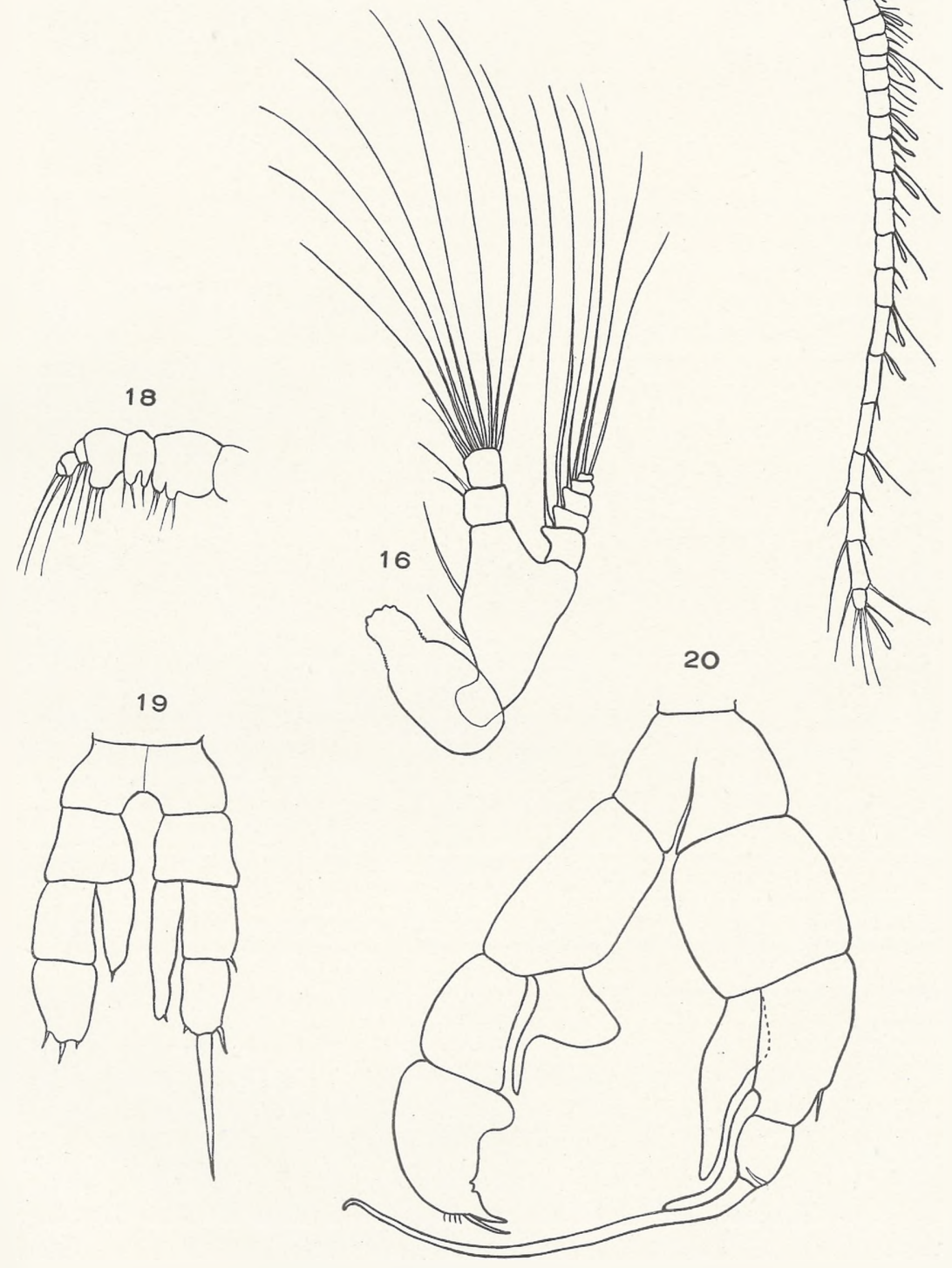

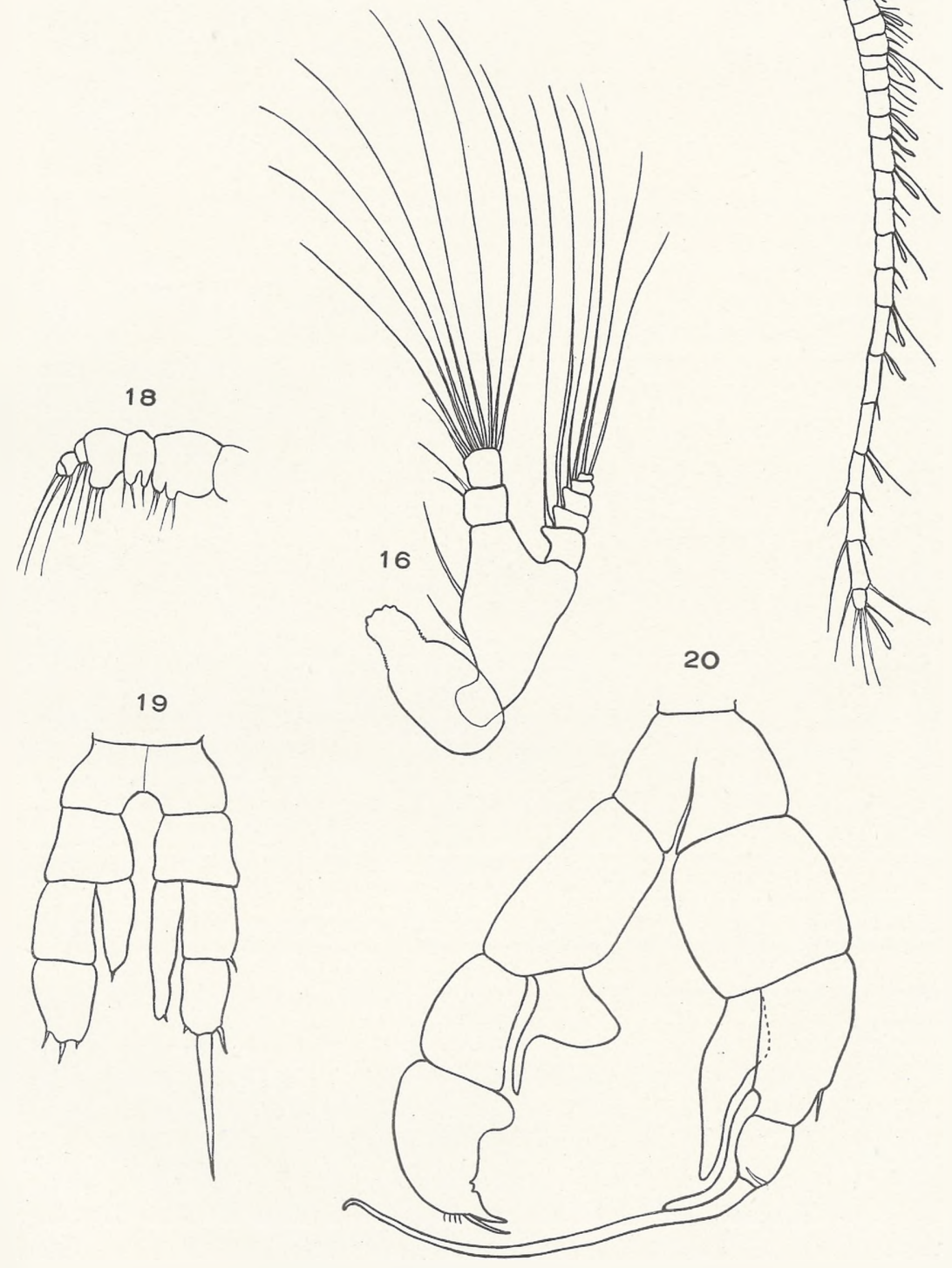

PROCEEDINGS, VOL. 66, ART. 4 PL. 3

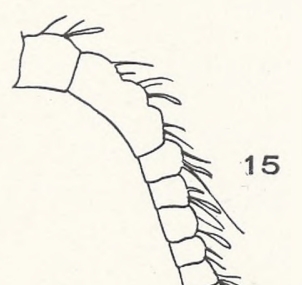

Male of Senecella calanoides

For EXPLANation of PLATE SEE PAGE 6 
rcin.org.pl 
rcin.org.pl 
rcin.org.pl 


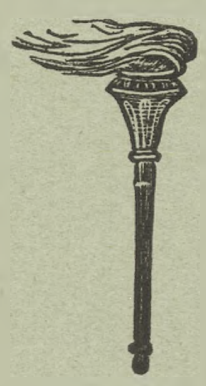

rcin.org.pl 